\title{
Sugarcane Leaf Tissue Sample Preparation for Diagnostic Analysis ${ }^{1}$
}

\author{
Ike V. Ezenwa, J. Mabry McCray, Peter R. Newman, and Ronald W. Rice ${ }^{2}$
}

Fertilizer management is an important agronomic practice in sugarcane production. When properly calibrated and timed, fertilizer applications provide essential nutrients for achieving high yields. Sugarcane requires 16 essential nutrients to complete its life cycle successfully. In addition, silicon, although not considered an essential nutrient, can provide additional benefits to the crop. [See Rice et al. 2002. (http://edis.ifas.ufl.edu/sc028) for information on the nutritional requirements for Florida sugarcane].

Sugarcane growers can use several best management practices (BMPs) as tools to help them deliver appropriate quantities of fertilizer nutrients to the crop for maximum nutrient utilization while also achieving economically favorable yields. These BMPs include the adoption of a consistent soil-testing program and the use of a leaf tissue (foliar) analysis program. The use of leaf analysis to assess nutrient needs of sugarcane should not be considered a replacement for a soil-testing program. Leaf analysis provides a snapshot of crop nutritional status at the time of sampling while soil testing provides predictive information about the soil's ability to continue to supply nutrients. Foliar analysis can reveal deficiencies before growth and yields are adversely affected, thereby permitting timely supplemental fertilizer applications to stimulate growth. On major sugarcane-growing soils of south Florida, supplemental fertilization of sugarcane during the grand growth period as suggested by DRIS indices increased cane and sugar yields (Elwali and Gascho, 1983; 1984). Overall understanding of the crop's nutritional status and fertilization needs will be improved by using both a calibrated soil test and a foliar analysis program. In addition, consideration of other factors (e.g. soil type, previous cropping/tillage history, field drainage properties) that affect plant growth and yield will also enhance one's ability to interpret crop nutrient requirements. This document will focus on sugarcane leaf tissue sampling for the purpose of foliar nutrient analysis and interpretation.

The Top Visible Dewlap (TVD) leaf blade is the plant tissue often used for sugarcane foliar analysis.

1. This document is SS-AGR-259, one of a series of the Agronomy Department, Florida Cooperative Extension Service, Institute of Food and Agricultural Sciences, University of Florida. Original publication date November, 2005. Visit the EDIS Web Site at http://edis.ifas.ufl.edu. This publication is also part of the Florida Sugarcane Handbook, an electronic publication of the Agronomy Department. For more information, you may contact the editor of the Sugarcane Handbook, R.A. Gilbert (ragilbert@ifas.ufl.edu). Visit the EDIS Web Site at http://edis.ifas.ufl.edu. http://edis.ifas.ufl.edu.

2. I.V. Ezenwa, Assistant Scientist, Agronomy Department, Southwest Florida Research and Education Center, Immokalee, FL.; J. M. McCray, Assistant Scientist, Agronomy Department, Everglades Research and Education Center, Belle Glade, FL.; P.R. Newman, Biological Scientist, Southwest Florida Research and Education Center, Immokalee, FL.; R. W. Rice, Agronomic Crops Extension Agent III, Palm Beach Co. Extension Office, Belle Glade, FL; Florida Cooperative Extension Service, Institute of Food and Agricultural Sciences, University of Florida, Gainesville, FL 32611. 
The TVD leaf is the uppermost fully expanded leaf that has a visible dewlap or distinct collar, a band of membranous tissue between the leaf sheath and the leaf blade (Figure 1). The TVD leaf has been the target leaf in establishment of standards of foliar analysis of sugarcane in Florida. The amount of nutrients in the TVD leaf compared to established standards or critical values will reveal whether the levels of the nutrients are adequate for growth and yield. Two methods are used to determine whether the levels of nutrients in the leaves are adequate for growth and yield. These are: (1) the Critical Value approach, and (2) the Diagnosis and Recommendation Integrated System (DRIS).

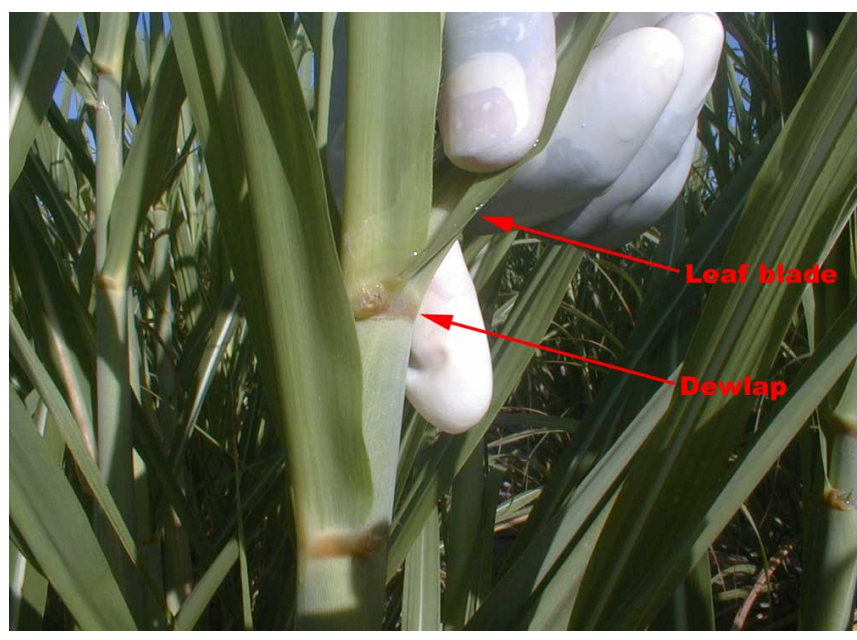

Figure 1. Top Visible Dewlap leaf blade is the preferred tissue for foliar analysis.

In the Critical Value approach, the critical value is defined as the nutrient concentration at production is limited. It is generally established on a response curve within the range of 90-95\% maximum yield. This approach may also include the use of the optimum range, defined as the range of nutrient concentration that is considered optimum for production. Within this range, a particular nutrient is not considered to limit production.

The DRIS calculates nutrient indices relative to zero by comparing leaf nutrient ratios with those of a high-yielding population. This approach incorporates a measure of the relationship between nutrients. It also has the advantage of not being as sensitive to the stage of growth as the Critical Value approach. Thus, DRIS allows a wider time frame during which to collect samples for foliar analysis.
The values or indices obtained from either the Critical Value approach or DRIS depend on whether the midrib is removed from the sampled leaf blade before analysis. The analytical values for most nutrients are lower when the midrib is included in the sample (Muchovej et al., 2005). It is advisable to remove the midrib in the sampling process because most critical values or standard indices have been developed using sampling methods that remove the midrib.

\section{Sampling Procedures}

Properly collected, representative leaf samples are necessary to obtain reliable analysis. To ensure that good samples are taken and properly handled, particular attention should be paid to organization and preparation before heading to the field to sample leaves. Assemble all the materials necessary for the sampling event (Figure 2), and establish a sampling label protocol that will be easily tracked in the field and laboratory. The following materials are recommended for sugarcane leaf tissue sampling: Pre-labeled grocery-sized paper bags to collect whole leaves in the field, distilled water to rinse the leaf blades, and smaller pre-labeled paper bags to store leaf blade samples in the drying oven.

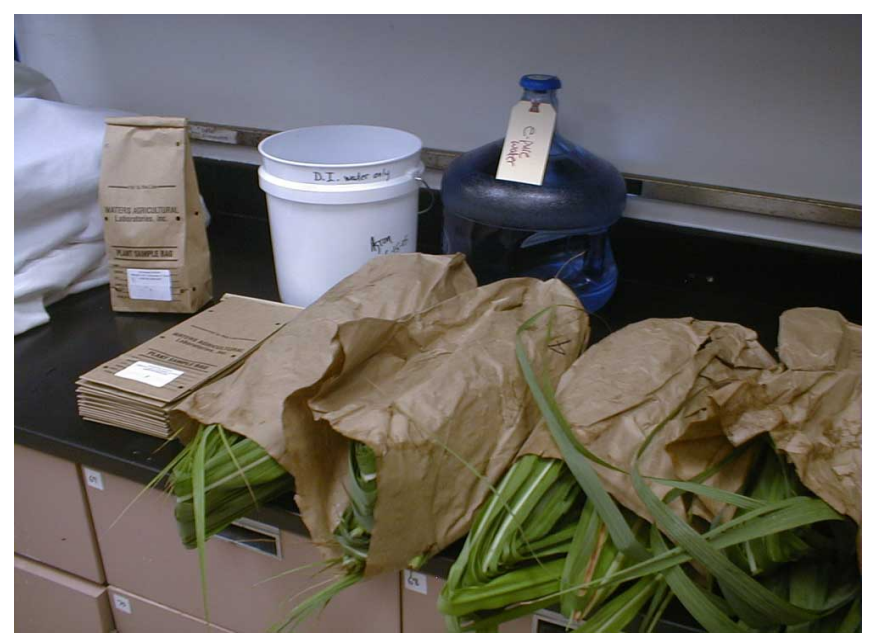

Figure 2. Gather all needed materials and label sampling bags by management unit

Typically, leaf sampling takes place during the grand growth period of sugarcane (between June and September in south Florida). Leaf samples should be taken from primary shoots or stalks, not from tillers or suckers, and be representative of the area being sampled. To collect a leaf sample, locate the TVD 
leaf, hold it near the base, and break the leaf from the sheath with a sharp downward motion. Care should be taken to avoid diseased plants or leaves with insect damage since diseased condition may affect the level of the nutrients in the leaves, and the interpretation of results.

Routinely, the sampling unit (geographic area to be sampled) should represent the field area that will be managed as a unit receiving similar production and management inputs, a so-called harvest or management unit. Where sugarcane growth is uniform across contiguous blocks (areas between field ditches) and will be treated as one management unit, two or more blocks may be sampled as one unit. Localized areas within a field showing poor growth or other unusual symptoms may need to be sampled separately. Several different sampling units may be identified within a single field, based on localized differences in drainage, soil type, plant health, and/or plant growth. Samples should be taken from plants that are at least $30 \mathrm{ft}$ away from the edge of the field or ditch and at least $100 \mathrm{ft}$ away from the end of the field unless these boundary areas are specific areas of concern. Soil parameters $(\mathrm{pH}$, etc.) within these field perimeter areas are often modified by in-field ditch and roadway spoils.

A suggested sampling pattern is to collect 16 leaves in a V-pattern in each of two locations on one end of a field. The V-pattern is accomplished by starting on one side of the block being sampled and moving across one or more rows as each leaf is sampled so that you move diagonally into and out of the field. If you begin sampling $100 \mathrm{ft}$ into the field and take a sample every $50 \mathrm{ft}$, this would take you approximately $450 \mathrm{ft}$ into the field to get the first 8 leaves before turning around and collecting 8 leaves on the way back. The two sub-samples of 16 leaves would be combined for a 32-leaf sample for analysis. Depending on uniformity of a field, a grower may decide to collect a separate sample of a particular portion of interest in the field. Sampling the entire length of a quarter or half-mile field should not be necessary to obtain a representative sample of the area. From a management standpoint, it may not be possible to subdivide a management unit, except when it is in line with grower objectives, and fertilizer recommendations can be applied directly to each sub-sampling unit. A grower needs to make the decision on the sampling unit based on the size of management unit and the proportion of the areas that show diversity in the features of interest.

During the entire sampling process, it is important that leaves be kept as clean as possible and that they are never placed directly on the ground. After a leaf sample is taken, it should be processed on the same day that it is collected. If processing cannot be done immediately, the sample should be placed in a paper bag, labeled, and kept out of the sun to prevent excessive moisture loss. A better method of keeping samples fresh is to place them in plastic bag inside a large cooler with ice. After removing midribs from leaf blades (Figure 3), leaf blades should be rinsed in distilled water to remove soil and dust particles that may contaminate the samples (Figure 4). Place rinsed samples in dry labeled sample bags ready for drying in the oven (Figure 5). Typically, leaf samples are dried in the oven at $125^{\circ} \mathrm{F}$. Depending on how the laboratory receives leaf tissue samples, the tissue may be ground (usually to pass a 1 $\mathrm{mm}$ screen) or sent out as dried, un-ground samples.

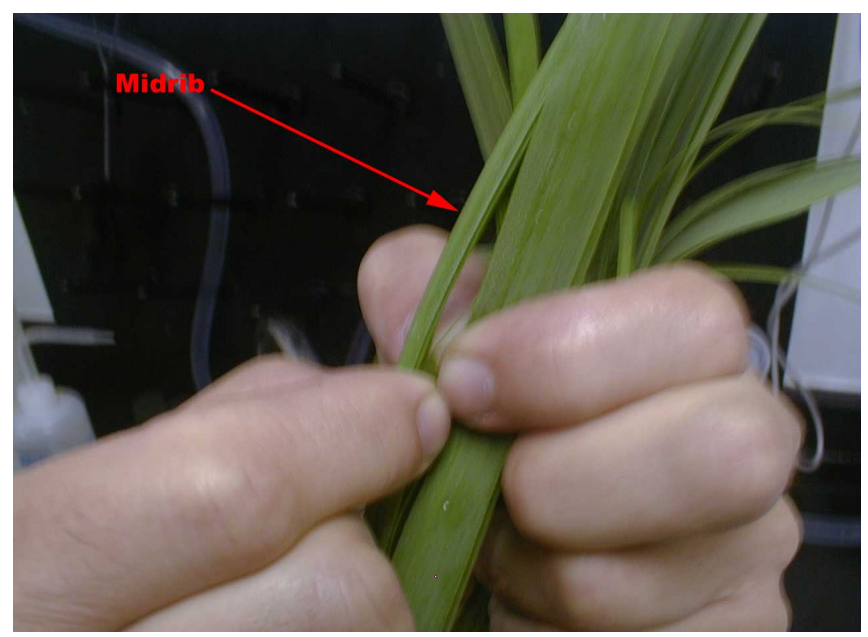

Figure 3. Removing the midrib from the leaf blade is a standard practice for sugarcane foliar analysis.

\section{Summary}

TVD leaf sampling and subsequent interpretation of the leaf tissue nutrient analysis can aid fertilizer recommendation for optimum growth and yield of sugarcane. Care should be taken to obtain representative samples. Leaf samples should be properly processed to ensure accurate results and interpretation of fertilizer requirements. 


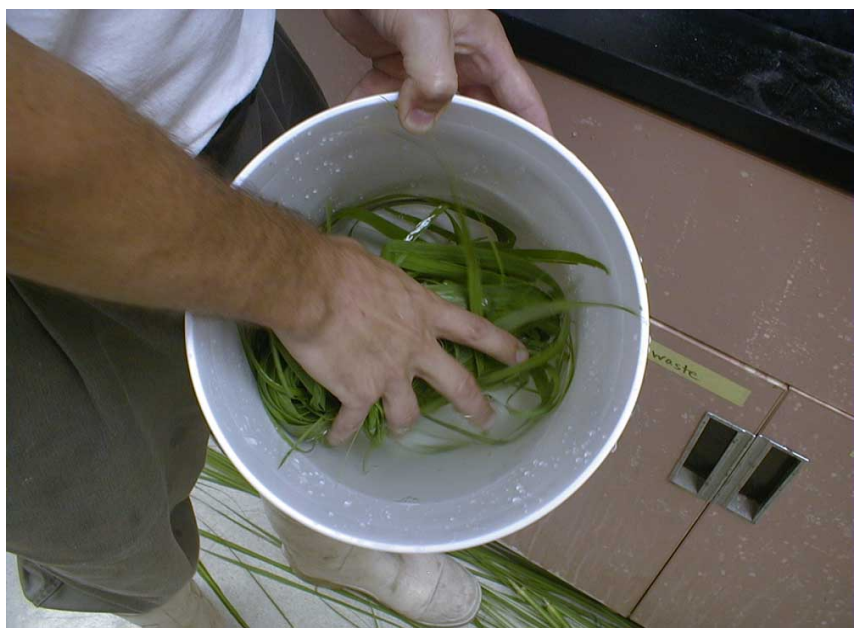

Rice, R.W., R.A. Gilbert, and R.S. Lentini. 2002. Nutritional requirements for Florida sugarcane. Florida Cooperative Extension Service Pub. SS-AGR-228. http://edis.ifas.ufl.edu/sc028

Samuels, G. (1969). Foliar Diagnosis for Sugarcane. Adams Press, Chicago. 362 pp.

Figure 4. Rinsing leaf blades to remove soil and dust particles.

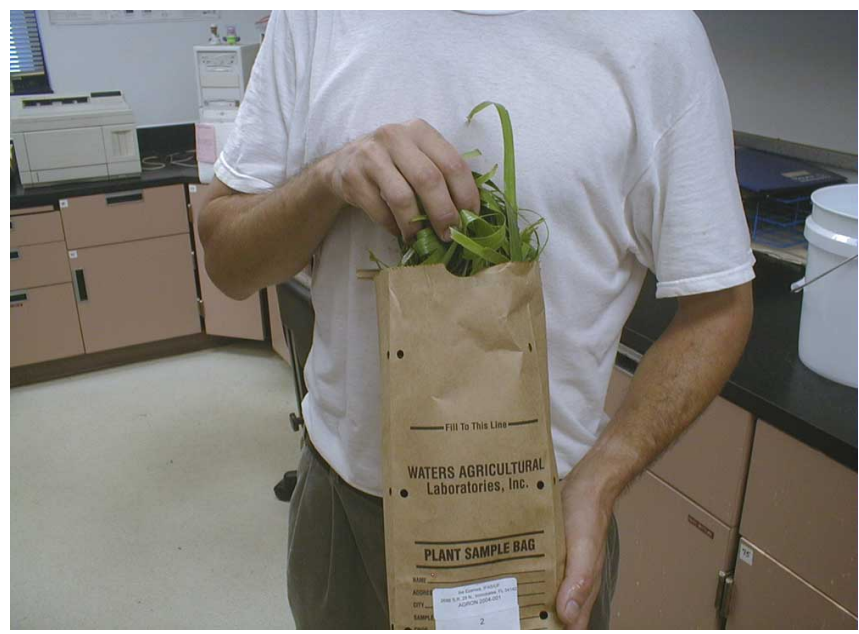

Figure 5. Place rinsed leaf blade samples in sample bags and put in a drying oven.

\section{References and further reading:}

Anderson, D. L. and J. E. Bowen. 1990.

Sugarcane Nutrition. Potash and Phosphate Institute. Atlanta, GA.

Elwali, A.M.O, and G.J. Gascho. 1983.

Sugarcane response to $\mathrm{P}, \mathrm{K}$, and DRIS corrective treatments on Florida histosols. Agron. J. 75:

79-83.

Elwali, A.M.O, and G.J. Gascho. 1984. Soil testing, foliar analysis, and DRIS as guides for sugarcane fertilization. Agron. J. 76: 466-470

Muchovej, R. M., P. R. Newman, and Y. Lou. 2005. Sugarcane leaf nutrient concentrations: with or without midrib tissue. J. Plant Nutri. 28:1271-1286. 